・论坛・ 中国国家公园试点专题

\title{
中国国家公园体制试点进展、问题及对策建议
}

\author{
李博炎 ${ }^{1,2}$, 朱彦鹏 ${ }^{1,2 *}$, 刘伟玮 ${ }^{1,2}$, 李爽 ${ }^{1,2}$, 付梦娣 1,2 , 任月恒 ${ }^{1,2}$, 蔡譞 ${ }^{1,2}$, 李俊生 ${ }^{1,2}$
}

1. 中国环境科学研究院生态科学研究所, 北京 100012; 2. 国家环境保护区域生态过程与功能评估重点实验室, 北京 100012

摘要: 建立国家公园体制是我国生态文明建设的重要内容, 是实现自然生态保护领域治理体系和治理能力现代化的重要举 措。2015年我国启动了国家公园体制试点工作，旨在为建立国家公园体制改革提供实践经验。为评估5年多来试点改革成效， 基于对10个国家公园体制试点开展的深入调研，发现：国家公园体制试点工作稳妥有序推进，在国家公园顶层制度设计、建 立管理体制机制、法规制度建设、生态环境治理、夯实保护管理基础等方面取得实质性进展，积累了一批可复制、可推广的 经验。但还存在一些问题，如法律、制度、标准相对欠缺，管理体制改革不到位，资金保障机制仍不成熟，生态环境监管制度 缺失，保护与发展矛盾依然明显等。为此，本文从推进法治体系建设、深化管理体制改革、构建多元化资金保障机制、健全 生态环境监管机制、促进国家公园共建共治共享等五个方面提出了对策建议，以期为2021年正式设立一批国家公园、初步建 立国家公园体制提供参考和依据。

关键词: 国家公园; 体制试点; 体制改革; 评估; 对策建议

李博炎, 朱彦鹏, 刘伟玮, 李爽, 付梦娣, 任月恒, 蔡譞, 李俊生 (2021) 中国国家公园体制试点进展、问题及对策建议. 生物多样性, 29, 283-289. doi: 10.17520/biods.2020258.

Li BY, Zhu YP, Liu WW, Li S, Fu MD, Ren YH, Cai X, Li JS (2021) Pilot areas for national park system in China: Progress, problems and recommendations. Biodiversity Science, 29, 283-289. doi: 10.17520/biods.2020258.

\section{Pilot areas for national park system in China: Progress, problems and recommendations}

Boyan $\mathrm{Li}^{1,2}$, Yanpeng $\mathrm{Zhu}^{1,2^{*}}$, Weiwei $\mathrm{Liu}^{1,2}$, Shuang $\mathrm{Li}^{1,2}$, Mengdi Fu${ }^{1,2}$, Yueheng Ren ${ }^{1,2}$, Xuan Cai ${ }^{1,2}$, Junsheng $\mathrm{Li}^{1,2}$ 1 Institute of Ecology, Chinese Research Academy of Environmental Sciences, Beijing 100012

2 National Environment Protection Library of Regional Ecosystem Structure and Services Evaluation, Beijing 100012

\begin{abstract}
Background: The establishment of national park system (NPS) is an important content of ecological civilization of China, and is an important measure to realize modernization of governance system and governance capacity in the field of natural and ecological protection. Aiming to obtain practical experience for reform of the NPS, central government of China launched pilot construction of the NPS in 2015.

Progress: For assessing efficiency of pilot reforms in the past five years, we carried out in-depth investigation and research in 10 national parks (NPs). The result showed that: pilot reform of the NPS was reliably and orderly promoted and accumulated a batch of replicable and propagable experience, especially on top design of the NPS, establishment of management mechanism, law and regulations construction, ecological environment protection, strengthening foundation of protection management. However, there was also relative lack of laws, regulations and standards. Management system reform of the NPS did not reach the designated position. It was also lack of monitoring system of ecological environment. Financial support was still not mature, contradictions between natural protection and society development were still obvious.

Perspective: This paper provides relational countermeasure and suggestion for law system construction, deepening the reform of management system, improving the ecological environment supervision mechanism, building diversified funds safeguard mechanism, and promoting to build, to manage and to share the NPs. This paper also provides reference and basis to formally build a batch of NPs, and to preliminary establish the NPS in 2021.
\end{abstract}

收稿日期: 2020-06-29; 接受日期: 2021-03-09

基金项目: 第二次青藏高原综合科学考察研究(2019QZKK0402)

* 通讯作者 Author for correspondence. E-mail: zhuyp@craes.org.cn 
Key words: national park; pilot areas; institutional reform; evaluation; recommendations

自2015年开始, 我国共设立了东北虎豹、祁连 山、大熊猫、三江源、海南热带雨林、武夷山、神 农架、普达措、钱江源、南山等10处国家公园体制 试点区(以下简称“试点”)。根据已印发的各试点总 体规划, 10 个试点共涉及 12 个省份的157处自然保 护地, 总面积约 22 万平方公里, 约占陆域国土面积 的2.3\%。2021年我国将正式设立一批国家公园，初 步建立国家公园体制。为此, 本文实地调研了 10 个 试点区试点改革及保护管理工作推进情况, 以问卷 形式对各试点社区居民进行访谈调查(李爽等, 2021), 同时本文对各试点建立以来至2020年通过 公开渠道刊发的新闻、规划、公报等资料进行梳理, 总结了试点工作取得的主要进展及有益经验, 分析 了面临的突出问题, 并有针对性地提出对策建议, 以期为推动实现国家公园体制改革目标任务, 加快 国家公园体制建设进程提供依据。

\section{国家公园体制试点的主要进展及经验}

1.1 国家层面完成了国家公园制度顶层设计, 明 确了建立国家公园体制改革方向和目标

2013年，党的十八届三中全会首次提出“建立 国家公园体制”, 引起了社会各界的广泛关注。2017 年9月, 中共中央办公厅、国务院办公厅印发了《建 立国家公园体制总体方案》, 明确了建立国家公园 体制的总体要求、目标任务和制度措施。2019年6 月, 中共中央办公厅、国务院办公厅再次印发了《关 于建立以国家公园为主体的自然保护地体系的指 导意见》, 提出建立分类科学、布局合理、保护有 力、管理有效的以国家公园为主体、自然保护区为 基础、各类自然公园为补充的中国特色自然保护地 体系。党的十九大报告提出 “建立以国家公园为主 体的自然保护地体系”。党的十九届五中全会再次 要求“坚持山水林田湖草系统治理, 构建以国家公 园为主体的自然保护地体系”。一系列国家顶层设 计文件的制定, 明确了建立国家公园体制改革在我 国生态文明体制改革中的重要地位, 也标志着我国 国家公园体制建设进入全面深化改革的新阶段, 成 为未来我国自然保护地体系建设的基础。

\section{2 初步确立了统一、分级的管理体制, 自然保护 地“九龙治水”问题得到改善}

2018年初, 党和国家机构改革方案有关文件明 确了国家公园等自然保护地管理与监管体制, 组建 了国家林业和草原局并加挂国家公园管理局牌子, 统一负责管理国家公园等各类自然保护地; 组建生 态环境部负责组织制定各类自然保护地生态环境 监管制度并监督执法。此次改革确定了国家公园统 一管理部门和监管部门, 基本实现“监管分离”, 改 变了以往自然保护地多部门、分要素管理的现象, 为建立国家公园体制奠定了很好的基础。在试点层 面, 10个试点整合了原有各类自然保护地的管理职 能, 均组建了统一的国家公园管理机构, 实行统一 管理(详见Box1)。试点的全民所有自然资源资产所 有权由中央政府和省级政府分级行使, 形成中央垂 直管理、中央和省级政府共管、委托省级政府管理 3 种管理模式。

\section{3 相继启动了法规制度建设, 编制总体规划, 推} 动国家公园制度化管理

各试点在缺少上位法支撑的情况下, 积极探索 和制定 “一园一规”。青海、福建、湖北及海南各省 分别颁布了《三江源国家公园条例(试行)》《武夷山 国家公园条例(试行)》《神农架国家公园保护条例》 《海南热带雨林国家公园条例(试行)》, 湖南省邵阳 市颁布了《南山国家公园管理办法》, 钱江源国家 公园管理局、开化县政府共同制订了《钱江源国家 公园管理办法(试行)》并颁布试行; 东北虎豹、祁 连山等试点草拟了国家公园管理办法, 正在启动立 法计划; 普达措试点在2013年发布的《云南省迪庆 藏族自治州香格里拉普达措国家公园保护管理条 例》的基础上，按照《建立国家公园体制总体方案》 要求, 正在修订《香格里拉普达措国家公园保护管 理条例》; 大熊猫试点已启动了管理办法的编制工 作。各试点条例确定了国家公园的管理体制、规划 建设、资源保护、利用管理、社会参与等主要内容, 为国家公园管理工作提供法治保障。各试点还建立 了相关管理制度和标准, 规范国家公园的运行管 理。如三江源试点印发了生态管护公益岗位、科研 


\section{Box 1 中国国家公园体制试点批复情况和管理模式}

- 东北虎豹国家公园体制试点: 于2017年1月正式获得批复，依托国家林业和草原局驻长春森林资源监督专员办事处组建 了东北虎豹国家公园管理局，由中央委托国家林业和草原局垂直管理。

- 祁连山国家公园体制试点: 于2017年9月正式获得批复，依托国家林业和草原局驻西安森林资源监督专员办事处组建祁 连山国家公园管理局，在甘肃省林业和草原局、青海省林业和草原局分别加挂省级管理局牌子，由中央和省级政府共同管 理。

- 大熊猫国家公园体制试点: 于2017年1月正式获得批复，依托国家林业和草原局驻成都森林资源监督专员办事处组建大 熊猫国家公园管理局, 在四川省林业和草原局、甘肃省林业和草原局、陕西省林业局分别加挂省级管理局牌子，由中央和 省级政府共同管理。

-三江源国家公园体制试点: 于2016年3月正式获得批复，组建了三江源国家公园管理局，作为青海省政府派出机构。

- 海南热带雨林国家公园体制试点: 于2019年7月正式获得批复, 在海南省林业局加挂海南热带雨林国家公园管理局牌 子, 由海南省政府垂直管理。

- 武夷山国家公园体制试点：于2016年6月正式获得批复，组建了武夷山国家公园管理局，由福建省政府垂直管理。

- 神农架国家公园体制试点: 于2016年5月正式获得批复, 组建了神农架国家公园管理局, 由湖北省政府垂直管理, 委托 神农架林区政府代管。

- 普达措国家公园体制试点: 于2016年10月正式获得批复, 组建了普达措国家公园管理局, 由云南省政府垂直管理, 委托 迪庆州政府代管。

- 钱江源国家公园体制试点: 于2016年6月正式获得批复，组建钱江源国家公园管理局，由浙江省政府垂直管理。

- 南山国家公园体制试点: 于2016年7月正式获得批复, 组建了南山国家公园管理局, 由湖南省政府垂直管理, 委托邵阳 市政府代管。

科普、访客管理等13个管理办法, 与《三江源国家 公园条例(试行)》构成“ $1+N$ ”政策制度体系; 云南省 制定了国家公园基本条件、建设规范、资源调查与 评价技术规程、管理评估规范、总体规划技术规程、 标志系统设置指南, 以及国家公园巡护技术规程等 多项技术标准, 印发了申报指南、管理评估指南等 管理政策, 对国家公园管理及相关制度的制定具有 一定的借鉴意义(唐芳林等, 2019)。在规划制定方面, 10 个试点总体规划均已获批, 其中三江源、神农架 试点因管控分区设置不符合 《关于建立以国家公园 为主体的自然保护地体系的指导意见》两个分区的 要求, 目前正在修编。各试点的总体规划均制定了 目标指标表, 确定了生态环境保护与修复、自然资 源管理、科研与监测、环境教育与生态旅游、社区 发展等方面的总体目标和分阶段目标, 根据主要保 护对象和重要自然生态系统等核心资源的种类、保 护价值、分布范围等划定了功能分区, 并规划了生 态系统保护修复、管理体制构建、教育游悡、社区 发展等专项内容。

\section{4 坚持“生态保护第一”的管理理念, 加大生态 环境整治力度}

各试点开展了一系列生态环境保育、修复和整 治工作, 突出了国家公园的严格保护。如三江源试
点取缔关闭砂石料场 113 家, 开展了黑土滩治理, 植被覆盖度增加到 $80 \%$ 以上; 祁连山试点出台了 《甘肃祁连山国家级自然保护区矿业权分类退出 办法》，按照“共性问题统一尺度、个性问题一矿一 策”的思路, 分类实施、有序退出, 同时规定了退出 范围、方式、时限、适用条件、程序及补偿标准。 祁连山试点共开展了 80 宗矿业权的退出, 并采取井 口封堵、采坑回填、植被恢复等方式, 恢复矿区生 态环境; 武夷山试点印发了《严厉打击违法违规开 垦茶山行为的通告》, 从严禁违法违规开垦茶山, 严禁挖掘机上山开垦林地, 严禁对违法违规开艮茶 山“黑名单”上的企业和个人进行扶持, 规范老茶山 改造等方面进行茶山整治, 共清退2008年12月以来 违法违规茶山7,300亩, 拔除茶苗30多亩, 完成生态 修复6,500亩, 拆除违规建设39处; 神农架试点拆除 制砖制砂设备21套、搅混设备2套、洗沙设备4套, 并 对破坏的山体进行恢复治理。

\section{5 稳步推进各项保护管理工作, 为保护国家公} 园生态环境夯实基础

各试点在自然资源和生态系统监测方面开展 了许多工作。如钱江源试点建成森林动态样地监测 平台、生物多样性与生态系统功能实验平台、网格 化生物多样性综合监测平台、林冠生物多样性监测 
平台等四大平台; 三江源、东北虎豹试点均建立了 “天空地一体化”监测体系, 监测范围涵盖了重要自 然生态系统及野生动植物分布范围和活动密集区 域，处于国内领先水平。在统一确权登记方面，各 试点基本完成了自然资源资产确权登记，明确界定 了各类自然资源资产的产权主体和边界。在集体土 地用途管制方面，武夷山、钱江源、南山等集体土 地占主体的试点探索创新了方式方法, 将集体林地 纳入统一空间用途管制范围。如钱江源试点以 48.2 元/亩·年的生态补偿标准, 完成27.5万亩集体林统 一管理, 并制定了原住民生产生活方式的正负面清 单。在社区共建共管方面, 三江源试点结合精准扶 贫，按照 “户均一岗” 原则，设置了17,211个生态管 护公益岗位，实现人均年增收2.16万元，使社区居 民享受生态保护带来的红利。

\section{面临的突出问题}

已建立的10个试点社会生态特征各有不同。如 三江源、普达措、祁连山、大熊猫等西部地区试点 处于青藏高原及周边地区，社会特征为多民族聚集， 生产生活方式相对单一, 且对自然资源依赖程度较 高, 经济发展水平相对落后。该类试点的改革难点 在于推动产业结构转型, 利用国家公园品牌效应发 展绿色经济, 拓宽社区居民增收渠道, 实现保护与 发展共赢。钱江源、武夷山、南山等中东部地区试 点范围内集体土地权属占比较大，分别为 $80.7 \%$ 、 $66.6 \% 、 64.54 \%$ 。该类试点的改革难点在于创新国 家公园土地权利多元化流转方式, 对集体土地进行 有效用途管制，实现国家公园自然资源统一管理。 此外，东北虎豹、大熊猫、祁连山作为跨省的试点, 改革难点在于统筹协调各方关系, 明确事权责任, 打通管理“堵点”, 构建高效的协同管理机制。特别 是东北虎豹试点, 作为唯一一个由中央直管的国家 公园, 保护管理职责由中央直接行使, 其建设模式 应具有较强的代表性, 能够为其他管理模式向中央 集中管理过渡提供改革范式。神农架、海南热带雨 林等试点具有优质的自然资源禀赋, 该类试点的改 革难点在于建立特许经营机制, 改革地方政府对旅 游经济的过度依赖, 并建立一定的利益分配机制, 平衡各方利益。

目前来看, 虽然各类试点针对上述改革重点和
难点, 开展了一些工作, 并取得了一定的成效, 但 仍存在一些问题，具体表现在以下几个方面。

\section{1 国家公园顶层法律、制度、标准欠缺, 对国家 公园建设的保障不足}

我国国家公园相关法律的制定总体上还较为 滞后，很多方面的考虑尚未达成一致意见。目前国 家公园试点区域管理工作仍依据《自然保护区条 例》等现行法规，难以适应新的管理要求，特别是 新划入的廊道等区域, 由于性质未明确, 缺少法律 保障，保护措施难落实。已颁布的多个国家公园地 方法规, 层级和效力较低, 且缺少上位法的指导, 管理要求、理念和内容差异性较大, 难以为国家公 园建设管理、自然生态系统保护和生态环境监管提 供法律保障。

\section{2 管理体制距“统一、规范、高效”的要求仍存在 一定的差距}

中央垂直管理的试点任务重、情况复杂，体制 改革难度较大。跨省试点区在工作的统筹协调方面 还需进一步加强，如个别试点管理机构依托原有保 护地或地方政府设立多个管理分局, 隶属关系复杂, 整合难度大, 机构运转效率不高。各片区分头推进 规划、考核、管护、监测等工作，管理条块分割。 同时，国家公园管理机构与辖区地方政府的关系尚 未厘清，职责出现交叉，存在改革不彻底的情况， 部分地方政府在国家公园保护和管理中没有发挥 应有作用，如部分试点的经营权仍由地方政府设立 的地方国有或国有控股的旅游开发公司掌握，没有 收归国家公园管理机构统一实行特许经营管理。

\section{3 国家公园多元化资金机制还不成熟，资金存 在较大缺口}

《自然资源领域中央与地方财政事权和支出 责任划分改革方案》提出根据建立国家公园体制试 点进展情况, 将国家公园建设与管理的具体事务分 类确定为中央财政事权与地方财政事权，中央与地 方分别承担相应的支出责任。《建立国家公园体制 总体方案》也提出建立财政投入为主的多元化资金 保障机制。但试点在资金方面的改革推进较缓慢, 国家层面尚未设立国家公园专项资金，原有自然保 护地的资金渠道仍占主导地位。目前，试点所涉及 的自然保护地来自财政的拨款渠道主要有两个: 本 级财政拨款和中央财政专项转移支付 (陈君帜, 
2020)。其中，本级财政拨款包括基本支出和项目支 出两部分, 已纳入本级财政预算。而中央财政的专 项转移支付十分有限, 还没有形成稳定持续的投入 机制。此外, 试点的资金来源渠道单一, 国家层面 和各试点还没有建立相应的投融资机制, 社会资本 参与国家公园保护管理缺乏相关法律和政策保障 (黄宝荣等, 2018)。

\section{4 国家公园生态环境监管机制尚未正式形成,} 监管作用未得到有效发挥

多数试点仍依托原有自然保护地的监测体系, 由各部门根据职责分头开展监测, 存在监测标准不 一、数据分散、共享程度不足、缺乏统一管理平台 等问题。国家公园管理部门和监管部门对试点的监 督检查工作多以集中式、突击式为主, 缺少常态化 定期的监督检查机制。在综合执法改革方面，国家 公园管理机构存在缺少行政执法权或执法权分散 等问题。如部分试点没有执法权, 仍由地方政府开 展行政执法工作, 遇到生态环境破坏行为, 管理机 构难以进行及时、有效监管。部分试点探索建立了 资源环境综合执法, 在一定程度上解决了执法监管
“碎片化”问题，但仍存在执法人员少、执法面积大、 执法手段落后等突出问题。

\section{5 保护与发展矛盾依然明显, 社区协同发展措} 施仍显不足

根据图1社区问卷调查结果显示, 除三江源试 点外, 各试点内社区居民利益诉求以 “提高收 入”“增加就业机会”“补偿方式多样化”等发展诉求 为主。各试点因限制以资源消耗为主的产业, 导致 社区经济短期内受到了影响。因此, 社区发展与国 家公园管理现阶段的矛盾根源是保护限制了自然 资源的开发利用, 进而在一定程度上制约了社区发 展(李爽等, 2020)。如部分试点停止了国家公园内采 伐、旅游、种植等经营性活动, 导致原从业居民收 入减少、生活质量下降, 对建立国家公园存在消极 看法。为缓解保护与发展矛盾, 试点制定了一些生 态补偿政策, 但效果不理想。如部分试点经营土地 等生产资料产生的收益高于生态保护补偿标准。此 外, 试点内不符合保护和规划要求的各类设施、工 矿企业退出工作整体推进缓慢, 补偿资金有较大缺 口，部分区域退出政策仍不明朗。

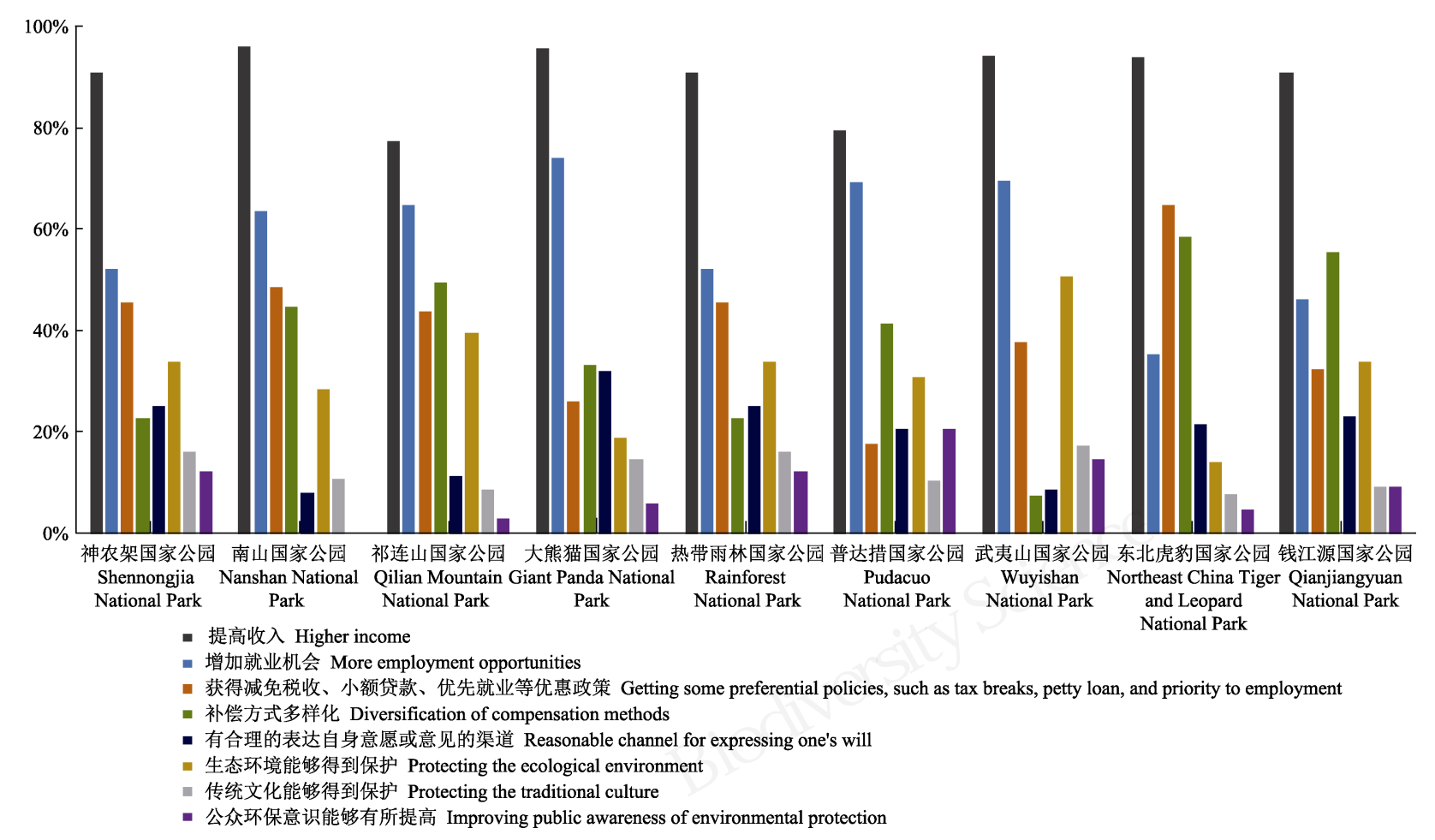

图19个国家公园的问卷调查中反映的社区居民对建立国家公园的主要诉求及其所占比重

Fig. 1 The community's main demand for a national park based on questionnaire in nine national parks 


\section{对策建议}

\section{1 推进法治体系建设, 提高治理水平和治理能力}

依法治理是建立国家公园体制的前提条件。建 议根据中央相关要求, 尽快出台《国家公园法》, 确 立国家公园自然资源保护、建设管护和生态环境监 管的各项制度, 落实各部门关于国家公园设立、建 设、管理和监督等事权划分和责任分工, 协同推进 国家公园法与自然保护地法之间的关系。坚持开门 立法, 充分吸收各方意见和建议, 做好论证, 提高 立法质量, 完善草案条文。提升国家公园法或自然 保护地法的法律效力位阶, 由行政法规或部门规章 上升到法律层面, 做好与现有上位法的衔接(李博 炎等, 2017)。健全国家公园法律制度体系, 构建包 括法律、条例、实施细则、标准规范等在内的体系 完备、操作性强的国家公园法律架构。制订或修订 地方性国家公园法规, 结合区域特征和管理需求, 出台更有针对性和操作性的条款。

\section{2 打破利益藩篱, 进一步深化管理体制改革}

建议进一步落实中央与地方事权划分, 可根据 事项性质和涉及地域范围、信息对称、激励相容等 原则, 将涉及规划编制、重要资源的修复和保护等 事项划归为中央事权, 如资源修复、国家公园总体 规划及专项规划编制等; 将涉及区域性的公共产品 和服务划归为地方事权, 如保护地的日常巡护、国 家公园管理机构基础设施建设等; 将涉及跨区域的 公共产品和项目划归为中央与地方共同事权, 如灾 害防治、外来物种防治等。对于省级政府代管的国 家公园, 管理权限不能再下放。此外, 在国家公园 建立过程中势必会触及到地方政府的既得利益, 为 使得改革推进过程中受到的阻力最小, 就需要正确 处理好国家公园管理机构和辖区地方政府的关系, 处理好短期利益与长远利益的关系。建议由国家公 园管理机构统一履行国家公园范围内的各项管理 职责, 采用特许经营的方式开展经营性活动, 严格 限制准入区域和项目清单。同时参照部分试点改革 模式, 将地方政府的领导班子成员同时作为国家公 园管理机构的主要负责人员, 以充分调动地方政府 在国家公园建设中的积极性。

\section{3 加快资金机制改革, 构建多元化资金保障机制}

事权决定财政支出。立足于国家公园的公益属
性, 通过合理划定中央和地方事权, 确定中央财政 和地方财政的支出责任。首先对于中央直管的国家 公园, 其支出全部由中央出资保障。对于中央和省 级政府共管及省级政府代管的国家公园，其支出则 应由中央和地方政府根据事权划分, 按照一定比例 分推支出责任。完善财政转移支付制度, 按国家公 园规模和保护成效等加大财政转移支付力度。在坚 持国家公园生态保护和公益属性前提下, 开展特许 经营等限制性经营活动，拓宽资金渠道。建立国家 公园基金会, 统一召集、接收和管理社会及国际捐 款, 同时与国家公园管理局建立合作关系, 确定、 资助和推进优先项目。开发国家公园绿色金融产品, 发行绿色彩票、绿色债券、绿色信贷, 同时, 可探 索将国家公园碳汇交易纳入全国碳排放交易市场, 拓宽国家公园资金渠道。

\section{4 实行监管分离, 健全生态环境监管机制}

改革保护地管理部门既是运动员又是裁判员 的管理模式, 强化国家公园生态环境监督管理职责, 构建“源头严防、过程严管、后果严惩”的全过程国 家公园生态环境监管制度体系(刘伟玮等, 2019)。建 议严格审批和监督国家公园的设立、调整、整合和 退出, 以及各类规划的落实情况等, 从源头实现预 防性保护。建立国家公园生态环境监测制度, 建设 国家公园“天空地一体化”生态环境监测网络体系, 开展国家公园生态环境监测和人类活动遥感监测, 定期发布国家公园生态环境状况报告。制定国家公 园生态环境保护成效评估的实施规程和相关标准, 定期开展国家公园生态环境保护成效评估, 统一发 布国家公园生态环境保护成效评估结果。依法授权 国家公园管理机构必要的行政执法和处罚职权。条 件允许的地区, 可参照部分试点改革经验, 推进国 家公园资源环境综合执法改革, 减少多头执法、重 复执法, 提高监管执法效能和水平。通过环境公益 诉讼、设立生态法庭等方式充分发挥检察院、法院 等机构在资源环境领域的司法监督职能, 强化资源 环境行政执法和刑事司法协作, 形成高效联动的综 合执法模式。

\section{5 协调人与自然和谐, 促进共建共治共享}

推行参与式社区管理模式, 通过设置生态管护 公益岗位、协议保护等方式, 鼓励社区居民参与生 态环境保护、社区服务等国家公园公共事务。针对 
部分国家公园集体土地占比较大的问题, 可结合农 村土地落实集体所有权、稳定农户承包权、放活土 地经营权的改革要求, 探索集体土地入股、托管、 协作共管等多种途径参与国家公园自然资源保护, 实现国家公园管理机构统一行使用途管制职责。同 时, 可借鉴国际经验, 探索通过协议、加盟等方式, 与周边其他自然保护地或相关区域形成统一布局、

互为补充的保护网络, 充分发挥国家公园带动周边 的核心作用, 将国家公园打造成区域协调发展的 “金字招牌” (苏红巧等, 2018)。打造国家公园品牌增 值体系, 建立完善绿色发展的产业链、创新链、价 值链, 扩大国家公园品牌辐射范围, 以吸纳社会企 业和个人加盟国家公园特许经营活动, 使国家公园 内外及加盟区实现责任共担、利益共享。

\section{参考文献}

Chen JZ, Tang XP (2020) Research on the establishment of National Parks Protection System in China. Journal of Beijing Forestry University (Social Sciences), 19(1), 1-11. (in Chinese with English abstract) [陈君帜, 唐小平 (2020) 中国国家公园保护制度体系构建研究. 北京林业大学学 报(社会科学版), 19(1), 1-11.]

Huang BR, Wang Y, Su LY, Zhang CL, Cheng DW, Sun J, He SY (2018) Pilot programs for national park system in China: Progress, problems and recommendations. Bulletin of Chinese Academy of Sciences, 33(1), 76-85. (in Chinese with English abstract) [黄宝荣, 王毅, 苏利阳, 张丛林, 程 多威, 孙晶, 何思源 (2018) 我国国家公园体制试点的进 展、问题与对策建议. 中国科学院院刊, 33(1), 76-85.]

Li BY, Li JS, Wei DY, Zhu YP (2017) International experience in legislation of national parks and enlightenments to China. Environment and Sustainable Development, 42(5), 20-23. (in Chinese with English abstract) [李博炎, 李俊生, 蔚东 英, 朱彦鹏 (2017) 国际经验对我国国家公园立法的启 示. 环境与可持续发展, 42(5), 20-23.]

Li S, Li BY, Liu WW, Fu MD, Ren YH, Zhu YP (2021) Discussion on the development path of national park community based on the interests of community residents. Issues of Forestry Economics, 4, doi: 10.16832/j.cnki.10059709.20200116. (in Chinese with English abstract) [李爽, 李博炎, 刘伟玮, 付梦娣, 任月恒, 朱彦鹏 (2021) 国家 公园基于社区居民利益诉求的社区发展路径探讨. 林业 经济问题, 4, doi: 10.16832/j.cnki.1005-9709.20200116.

Li S, Liu WW, Fu MD, Li BY, Ren YH, Zhu YP (2020) Current problems, challenges and countermeasures of community development in nature reserves. Environment and Sustainable Development, 45(3), 130-133. (in Chinese with English abstract) [李爽, 刘伟玮, 付梦娣, 李博炎, 任 月恒, 朱彦鹏 (2020) 自然保护区社区发展存在的问题、 挑战及对策研究. 环境与可持续发展, 45(3), 130-133.]

Liu WW, Quan ZJ, Luo JW, Zhu YP (2019) Ecological supervision function and suggestions on system construction in the new period. Research of Environmental Sciences, 32, 1259-1263. (in Chinese with English abstract) [刘伟玮, 全 占军, 罗建武, 朱彦鹏 (2019) 新时期生态监管职能解析 及制度体系构建建议. 环境科学研究, 32, 1259-1263.]

Su HQ, Su Y, Wang YF (2018) A mirror of French national park system reform. China Policy Review, (1), 68-71. (in Chinese) [苏红巧, 苏杨, 王宇飞 (2018) 法国国家公园体 制改革镜鉴. 中国经济报告, (1), 68-71.]

Tang FL, Yan Y, Liu WG (2019) Construction progress of national park system in China. Biodiversity Science, 27, 123-127. (in Chinese with English abstract) [唐芳林, 间颜, 刘文国 (2019) 我国国家公园体制建设进展. 生物多样 性, 27, 123-127.]

(责任编委: 徐卫华 责任编辑: 时意专) 